\title{
A note on the visual cliff behavior of rats following ECS*
}

\author{
CHARLES F. HINDERLITER $\dagger$ and JAMES R. MISANIN \\ Susquehanna University, Selinsgrove, Pennsylvania 17870
}

\begin{abstract}
The visual cliff behavior of two strains of male and female rats given ECS was compared with that of animals not given ECS at 6 and $24 \mathrm{~h}$ after treatment. Overall sex and strain differences obtained, whereas no overall difference occurred between experimental (ECS) and control (no ECS) animals. There was, however, a difference between the behavior of the animals given ECS $6 \mathrm{~h}$ prior to testing and that of animals given ECS $24 \mathrm{~h}$ before testing. These results are related to use of the step-down passive avoidance task for assessing the amnestic effects of ECS on learned responses.
\end{abstract}

The one-trial step-down passive avoidance (PA) task is commonly used to assess the so-called amnestic effects of electroconvulsive shock (ECS) on learned responses. This task, however, entails perception of depth cues, and ECS has been shown to affect animals' perception in certain situations (e.g., Misanin \& Lewis, 1970). Also, it has been shown that animals given ECS descend from a platform faster than animals not given ECS (Routtenberg \& Kay, 1965), and speed of descent is the measure used to assess the post-ECS retention deficit in the step-down situation. Thus, whether or not depth perception is altered by ECS, and, hence, whether or not the post-ECS retention deficit in the step-down PA situation can, in part, be attributed to impaired depth perception, should be determined. Toward this end, the present experiment examined the effect of ECS on the visual cliff behavior of albino and black rats.

\section{METHOD}

\section{Subjects}

Eighty Long-Evans black and 80 Wistar albino rats, born and reared in the Susquehanna University animal colony, were used. Half of the rats of each strain were males weighing 228-414 g and half were females weighing $168-296 \mathrm{~g}$. They were housed individually and maintained on a 10 -g daily ration of Purina Lab Chow with free access to water.

\section{Apparatus}

A visual cliff (Lafayette Instrument Co.) was used. It consisted of two $15 \times 30$ in. glass plates placed side by side, $81 / 2$ in. from the top of four checkered patterned (2-in. red and white squares) walls. Directly beneath one plate (shallow side) and 16 in. beneath the other (deep side) were similar checkered patterns. Dividing these deep (D) and shallow (S) sides was a similarly patterned $30 \times 2 \frac{1}{2} \times 3 / 4$ in. platform situated 3 in. above the glass plates. A $150-\mathrm{W}$ incandescent light. 50 in. above the platform and $14 \mathrm{in}$. above a broadcloth canopy, provided $1 \mathrm{fc}$ of diffuse light at the plate level. The canopy hung down 16 in.

*This research was supported by PHS Research Grant MH 17207 from the National Institute of Mental Health. Requests for reprints are to be sent to James R. Misanin. Department of Psychology, Susquehanna University. Selinsgrove. Pennsylvania 17870.

$\div$ Now at Kent State University. away from three of the walls of the apparatus and served to reduce extraneous visual stimulation. Cheesecloth was draped 16 in. away from the remaining wall so that the behavior of $S$ could be observed.

Electroconvulsive shock and pseudo-ECS were given in a $11 \frac{1 / 2}{2}$ $\mathrm{x} 10^{1 / 2} \times 8$ in. Plexiglas box with a grid floor that was enclosed in a metal chest (Grason-Stadler, Model E3125A-300). A .5-sec $55-\mathrm{mA} 60-\mathrm{Hz}$ shock (ECS) was administered through modified alligator clips suspended through holes in the chest and box and attached to S's ears.

\section{Procedure}

On each of the 2 days prior to ECS or pseudo-ECS, Ss were weighed and handled for $5 \mathrm{~min}$. On the treatment day, equal numbers of Ss from both strains and sexes were weighed and given either ECS or pseudo-ECS (attached earclips but no ECS) and immediately returned to their home cages. The criterion for a convulsion was rigid hindward extension of the rear legs. Animals failing to meet this criterion were replaced. Half of the ECS (experimental) and half of the pseudo-ECS (control) animals were tested $6 \mathrm{~h}$ after treatment and half $24 \mathrm{~h}$ after treatment. Testing consisted of placing $S$ upon the central platform of the visual cliff apparatus and recording side (S or D) and latency of descent, i.e., the time in seconds it took $S$ to descend from the platform and place all four feet on one of the plates. If $\mathrm{S}$ did not descend from the platform within $5 \mathrm{~min}$, it was assigned a latency of $300 \mathrm{sec}$ and no descent $(\mathrm{N})$ was recorded. Both sides of the apparatus were cleaned with a detergent after the testing of each animal.

\section{RESULTS AND DISCUSSION}

A 2 by 2 by 2 by 2 analysis of variance was performed on a reciprocal transformation of the latency data with strain, sex. ECS-treatment, and treatment-test interval being the factors under consideration. No overall significant difference among groups was found $(\mathrm{F}=$ 1.29. $\mathrm{df}=15.159 . \mathrm{p}>.1$ ). This finding runs contrary to that of Routtenberg and Kay (1965), who found that animals given ECS tended to step from a platform faster than controls (no ECS) $6.8 \mathrm{~h}$ after treatment. This discrepancy may have been due to, among other things, the size of the platform or amount of extraneous stimulation. but. in any case. indicates the lack of transsituational generality of their finding. This is not surprising, since they also obtained discrepant results in the two experiments performed in which the sizes and 
Table 1

Number of Ss Descending to the Shallow (S) and Deep (D) Sides of the Visual Cliff and Number of Ss Failing to Make a Descent (N)

\begin{tabular}{|c|c|c|c|c|c|c|c|c|c|c|c|c|}
\hline & \multicolumn{6}{|c|}{6 Hour } & \multicolumn{6}{|c|}{24 Hour } \\
\hline & \multicolumn{3}{|c|}{ Male } & \multicolumn{3}{|c|}{ Female } & \multicolumn{3}{|c|}{ Male } & \multicolumn{3}{|c|}{ Female } \\
\hline & D & $\mathbf{N}$ & $\mathbf{S}$ & D & $\mathrm{N}$ & $\mathrm{S}$ & D & $\mathbf{N}$ & $\mathbf{S}$ & D & $\mathrm{N}$ & $\mathrm{S}$ \\
\hline & \multicolumn{12}{|c|}{ Long-Evans (Black) } \\
\hline Experimental & 2 & 5 & 3 & 3 & 3 & 4 & 5 & 1 & $\begin{array}{l}4 \\
5\end{array}$ & 3 & 0 & 7 \\
\hline \multirow{2}{*}{ Control } & 4 & 2 & 4 & 4 & 2 & 4 & 4 & 1 & 5 & 4 & 0 & 6 \\
\hline & \multicolumn{12}{|c|}{ Wistar (Albino) } \\
\hline $\begin{array}{l}\text { Experimental } \\
\text { Control }\end{array}$ & 1 & 5 & 4 & 3 & 2 & 5 & 2 & 3 & 5 & 3 & 1 & 6 \\
\hline Control & 2 & 4 & 4 & 2 & 0 & 8 & 2 & 6 & 2 & 1 & 3 & 6 \\
\hline
\end{tabular}

heights of the platforms differed (Routtenberg \& Kay. 1965).

Chi-square analyses were used for making statistical comparisons of group frequency data (Table 1) by collapsing over the levels of variables not included in the specific comparison. No significant differences were found between strains or between the sexes on side of descent $\left(\chi^{2} s \leqslant 3.07\right.$. dfs $=1$, ps $\left.>.05\right)$, a finding that is somewhat in agreement with that of Walk and Gibson (1961), who reported no difference in the visual cliff behavior of hooded and albino rats. However, when all three categories (S, D, and $\mathrm{N})$ were considered, overall $\operatorname{sex}\left(\chi^{2}=8.84, \mathrm{df}=2, \mathrm{p}<.05\right)$ and strain $\left(\chi^{2}=6.51, \mathrm{df}\right.$ $=2, \mathrm{p}<.05)$ differences obtained. More black $(\mathrm{N}=29)$ than albino $(\mathrm{N}=16)$ rats descended to the deep side. whereas more albino $(\mathrm{N}=24)$ than black $(\mathrm{N}=14)$ remained on the platform. Similarly, more male $(\mathrm{N}=27)$ than female $(\mathrm{N}=11)$ rats failed to step down. Whether or not failure to leave the platform in this situation can be used as an index of emotionality or fear cannot be determined from the present data; this difference between strains and between the sexes should, however, be given some consideration when selecting animals to use in a step-down PA task.

The main findings of interest for the purpose of this study are (a) in both the experimental and control groups, a significantly greater number of Ss descended to the shallow rather than to the deep side $\left(\chi^{2} s \geqslant 4.13\right.$, dfs $=1$, ps $<.05$ ), and (b) no overall significant difference obtained between experimental and control animals $\left(\chi^{2}\right.$ $=0.14, \mathrm{df}=2, \mathrm{p}>.05)$. Jointly, these findings indicate that ECS does not impair the depth perception of rats, and, hence, impaired depth perception cannot account for the post-ECS retention deficit in the step-down PA situation. It was noted, however, that a significantly $\left(\chi^{2}\right.$ $=6.67, \mathrm{df}=1, \mathrm{p}<.05)$ greater number of the experimental animals remained on the platform at $6 \mathrm{~h}$ after ECS $(N=15)$ than at $24 \mathrm{~h}$ after $\operatorname{ECS}(\mathrm{N}=5)$, a difference that did not occur among controls $\left(\chi^{2}=0.28\right.$, $\mathrm{df}=1, \mathrm{p}>.05)$. This finding has important implications for those interested in investigating the transsituational generality of the delayed development of amnesia that has been shown to occur in the step-through PA situation (e.g., Geller \& Jarvik, 1968; McGaugh \& Landfield, 1970).

\section{REFERENCES}

Geller, A., \& Jarvik, M. E. The time relations of ECS induced amnesia. Psychonomic Science, 1968, 12, 169-170.

McGaugh, J. L., \& Landfield, P. W. Delayed development of amnesia following electroconvulsive shock. Physiology \& Behavior, 1970, 5, 1109-1113.

Misanin, J. R., \& Lewis, D. J. Sensitivity and reactivity to foot shock following electroconvulsive shock stimulation. Physiology \& Behavior, 1970, 5, 397-405.

Routtenberg, A., \& Kay, K. E. Effect of one electroconvulsive seizure on rat behavior. Journal of Comparative \& Physiological Psychology, 1965, 59, 285-288.

Walk, R. D., \& Gibson, E. J. A comparative and analytical study of visual depth perception. Psychological Monographs, 1961, 75(15, Whole No. 519).

(Received for publication July 3, 1972; accepted December 21, 1972.) 